\title{
Filosofia E EDUCAÇÃO: CRÍTICA FOUCAULTIANA \\ POR VIAS EPISTEMOLÓGICAS DA FILOSOFIA DA RESISTÊNCIA*
}

\author{
José Pascoal Mantovani \\ Universidade Metodista (UMESP) - São Bernardo - São Paulo
}

\begin{abstract}
RESUMO
Este artigo tem como objeto de pesquisa o tema da filosofia e educação, bem como a idiossincrasia destes dois tópicos. Como objetivo geral deste trabalho, espera-se apresentar caminhos epistemológicos relacionados a filosofia da Educação a partir da constituição da subjetividade do filósofo francês Michel Foucault (2018). Os objetivos específicos serão: (i) apresentar a relação indissociável entre filosofia e educação a partir de contribuições kantianas (1996) e de Adorno (2014); (ii) destacar a dimensão da subjetividade em Foucault (2018) e sua abordagem sobre a constituição do sujeito que traz o duplo existencial (do si mesmo para o outro); (iii) destacar o impacto da resistência filosófica quando feita a partir de uma epistemologia que lança o sujeito para o centro da reflexão. A problematização que pautará a reflexão deste artigo será: Qual o papel da educação na construção da subjetividade do sujeito? Com essa pergunta, espera-se propor caminhos hermenêuticos que auxiliem no processo educacional. A metodologia deste trabalho é a revisão bibliográfica do autor Michel Foucault e comentarista como Edgarbo Castro (2016) e Veiga-Neto (2000).
\end{abstract}

Palavras-chave: Foucault; Epistemologia; educação.

* Trabalho apresentado na II Semana de Filosofia da Universidade Metodista de São Paulo. São Bernardo do Campo, SP, 14-17 out. 2019.

** Doutor em Educação; Mestre em Ciências da Religião; Graduado em Teologia e Filosofia pela Universidade Metodista de São Paulo (UMESP). E-mail: jose.junior20@ metodista.br. 


\section{INTRODUÇÃo}

O princípio lógico aristotélico contribui para a percepção não só da coisa em si, sobretudo de todos os atributos que são inerentes a esta coisa. Dentre tantas compreensões, ater-se para o "télos" da coisa é fundamental, ou seja, compreender a finalidade para que algo está posto. Está compreensão teleológica perpassa as dimensões concretas e abstratas, o imanente e o transcendente. Logo, pensar sobre a humanidade é ponderar, dentre tantas variáveis aspectos que são imprescindíveis, ainda que não mensuráveis ou palpáveis. Um destes elementos indispensáveis é a educação. Ainda que as temáticas sejam alteradas, desde a noção da "Paidéia" grega, até as abordagens contemporâneas sobre educação, insistem na ideia de que o ser humano é inacabado e que se constrói a partir da educação. Assim, a pergunta problematizadora deste artigo, como dito anteriormente, é: qual o papel da educação na constituição da subjetividade dos sujeitos? A hipótese perpassa a ideia de fomentar a resistência diante dos mecanismos colonizadores. O recorte desta pesquisa se aterá a contribuição de Kant (1996) e Adorno (2014) ao que tange o tema da educação. A escolha destes autores é sua relação direta com os textos e produções foucaultianas. Em um primeiro momento, será posta as contribuições kantianas e, em seguida, provocações de Adorno também voltado ao tema da educação.

\section{Kant e Adorno: provocações educativas}

Immanuel Kant é reconhecido como um autor responsável pela ruptura temporal do ato de fazer filosofia. Três perguntas acompanham suas produções acadêmicas: o que é o belo? O que é possível conhecer? E o que é ética? Perguntas atreladas à estética, à epistemologia e à deontologia demonstram a densidade teórica de Kant, contudo, há outra contribuição deste autor para a filosofia que está agarrada ao tema da educação. Em sua obra "Sobre a Pedagogia", Kant inicia com a afirmação: "o homem é a única criatura que precisa ser educada" (1996, p. 11), ou seja, é um ser incompleto e envolto as possibilidades existenciais das contingências humanas. 
Segundo Kant, a educação é viabilizada por meio da disciplina, interpretando este conceito como aquilo que "transforma a animalidade em humanidade" (1996, p. 12). A disciplina em categorias kantianas é o que lança o sujeito para a relação humana, ou seja, coloca o sujeito em um processo de humanização. Ao mesmo tempo que a disciplina é elemento condicionante do sujeito aos imperativos humanos, é por meio da disciplina que o sujeito se descola de sua identidade primeira, do estado de natureza. Ainda que o Estado de Natureza tenha nobreza em si mesmo, a vida em sociedade exige interação social, a qual é possível apenas por meio da ação consciente do ser que sai da condição da selvageria por meio da disciplina, como destaca Kant:

A selvageria consiste na independência de qualquer lei. A disciplina submete o homem às leis da humanidade e começa a fazê-lo sentir a força das próprias leis. Mas isso deve acontecer bem cedo. Assim, as crianças são mandadas cedo à escola, não para que aí aprendam alguma coisa, mas para que aí se acostumem a ficar sentadas tranquilamente e a obedecer pontualmente àquilo que lhes é mandado, a fim de que no futuro elas não sigam de fato e imediatamente cada um de seus caprichos (1996, p. 13).

A provocação de Kant, ainda que atende a noção de utilidade, aponta como a disciplina é dispositivo de adestramento e docilização do sujeito. Permanecer na selvageria é prejudicial a condição humana. Portanto, para Kant, o homem não pode se tornar um verdadeiro homem senão pela educação. Ele é aquilo que a educação dele faz. Note-se que ele só pode receber tal educação de outros homens, os quais receberam igualmente de outros. Portanto, segundo Kant (1996), a falta de disciplina e de instrução em certos homens os torna mestres muito ruins de seus educandos. Nota-se grande preocupação por parte do filósofo quando falta disciplina:

Não há ninguém que, tendo sido abandonado durante a juventude, seja capaz de reconhecer na sua idade madura em que aspecto foi descuidado, se na disciplina ou na cultura (pois que assim pode ser chamada a instrução). Quem não tem cultura de nenhuma espécie é um bruto; quem não tem disciplina ou educação é um selvagem. A falta de disciplina é um mal pior que a falta de cultura, pois esta pode ser remediada mais 
tarde, ao passo que não se pode abolir o estado selvagem e corrigir um defeito de disciplina. (KANT, 1996, p. 16).

É neste ponto que será posto relação entre Kant e Adorno. Em seu texto "Educação e Emancipação" (2014), Adorno destaca que a educação segue por vias bastante paradoxais, se por um lado ela pode ser a forma de auxiliar o sujeito a transpor os limites da selvageria, por outro lado, a educação pode ser a legitimação racional da irracionalidade, ou seja, o adestramento lógico e sistemática da barbárie. Para Adorno, "a própria falta de emancipação é convertida em ideologia, tal como o faz a juventude que, surpreendida em qualquer ato de violência, procura se librar apelando à sua condição de teenager adolescente. (2014, p. 35), ou seja, ao passo que a educação é um fator voltado para atos disciplinadores, o risco é deixar cativa a educação em um sistema que estabelece molduras, ainda que bem justificadas.

Entra em cena a figura do docente nessa relação, ou seja, ele demonstra como a docência está repleta de indecência ou, ao menos, sem credibilidade ou seriedade. Qual é, pois, a função do docente no processo formativo? Adorno destaca que os docentes, durante anos, estiveram preocupados com a eficácia da ação educativa, mas não com a educação em si. 0 autor demonstra como projetos pedagógicos, em resposta a eficiência e eficácia, pode ser um mecanismo de desumanização da humana, como destaca Adorno:

Lembro que durante o processo sobre Auschwitz, em um de seus acessos, o terrível Boger culminou num elogia à educação baseada na força e voltada à disciplina. Ela seria necessária para construir o tipo de homem que lhe parecia adequado. Essa ideia educacional da severidade, em que irrefletidamente muitos podem até acreditar, é totalmente equivocada. A ideia de que a virilidade consiste num grua máximo da capacidade de suportar dor de há muito se converteu em fachada de um masoquismo que - como mostrou a psicologia - se identifica com muita facilidade ao sadismo. 0 elogiado objetivo de "ser duro" de uma tal educação significa indiferença contra a dor em geral. P. 128

A disciplina serve não para o processo de humanização, mas que atenda ao ideal prometeico de transformar a subjetividade do sujeito 
em consciência coisificada. A disciplina é, assim, a maneira de fazer com que o sujeito se desnude de sua identidade a fim de assumir estigma socialmente aceito, coletivo, plural que nega o singular. Tal ação faz com que o sujeito perca a si mesmo nos excessos típicos da coletividade, como aponta Adorno:

Pessoas que se enquadram cegamente em coletivos convertem a si próprios em algo como um material, dissolvendo-se como seres autodeterminados. Isto combina com a disposição de tratar outros como sendo uma massa amorfa. Para os que se comportam dessa maneira utilizei o termo 'caráter manipulador' [...] (2014, p.129)

Adorno deixa claro como a noção de antinomia está presente na constituição da subjetividade, tornando, assim, o sujeito refém da heteronomia que favorece a condição de menoridade e de dependência. Assumir o coletivismo a partir de práticas disciplinares, ainda que seja funcional no processo de domesticação da subjetividade do sujeito, por outro lado, salta a importância da educação como elemento axiológica na construção do si mesmo, bem como das noções intersubjetividades que perpassam a existência humana, como será destaca a seguir.

\section{A SUBJETIVIDAdE FOUCAULtiana}

Em categorias foucaultianas, subjetividade é "a maneira pela qual o sujeito faz a expe-riência de si mesmo num jogo de verdade, no qual ele se relaciona consigo mesmo" (FOU-CAULT, 2004, p. 236). Revel comenta que "se o sujeito se constitui, não é sobre o fundo de uma identidade psicológica, mas por meio de práticas que podem ser de poder ou de conheci-mento, ou ainda por técnicas de si” (2011, p. 147). Segmentar ou restringir a constituição da subjetividade por uma única via é, sobretudo, um esforço reducionista da complexidade ine-rente à formação do indivíduo. Seguindo por este viés, Revel demonstra que o sujeito é com-posto de um contínuo devir, isto é, um regime de constante mutação e transformação. Em ou-tras palavras: 
esse lugar inassinalável da subjetividade em movimento, em perpétuo 'desprendimento' em relação a ela mesma, é, ao mesmo tempo, para Foucault, o produto das determinações históricas e do trabalho sobre si (cujas modalidades são, por seu turno, históricas), e é nessa dupla ancoragem que se enlaça o problema da resistência subjetiva da singularidade: o lugar da invenção do si não está no exterior da grade do saber/poder, mas na sua torção íntima - e o percurso filosófico de Foucault parece aí, para nós, disso dar o exemplo (2011, p. 147).

Portanto, tratar de subjetividade do sujeito em Foucault é lançar-se em um oceano hermético em que arvorar-se juízos pré-formativos com o intento de prestigiar todas as dimensões que beneficiam a elaboração da constituição última do ser. Não é possível sintetizar o sujeito em uma ou outra coisa, isto é: em um ser transcendental ou empírico; objetivo ou abstrato; enfim, a subjetividade do sujeito carrega a densidade do duplo que é intrínseco ao ser. Só é possível compreender a subjetividade do sujeito a partir de uma abordagem dialógica, aberta e expansiva que elucubra o ser em sua integralidade. Entrelaçaremos, assim, o tema da subjetividade foucaultiana com as contribuições de Kant e Adorno para uma compreensão epistêmica da resistência como vias constitutivas.

\section{A EPISTEMOLOGIA DA RESISTÊNCIA: CAMINHOS (DE)FORMATIVOS}

Ainda que os textos de Michel Foucault não estejam entrelaçados diretamente com a ideia da Educação estritamente, é possível, sem grandes manobras, aproximar o texto foucaultiano das abordagens educacionais. Pensar, então, a resistência como elemento epistemológico, é, em primeiro lugar, apontar para "uma determinação temporal e geográfica" (CASTRO, 2016, p. 139); em segundo lugar "descrever a episteme é descrever a região intermediária entre os códigos fundamentais de uma cultura, os que regem sua linguagem, seus esquemas perceptivos, seus intercâmbios, suas técnicas, seus valores, a hierarquia de suas práticas, e as teorias, científicas e filosóficas, que explicam todas essas formas de ordem" (CASTRO, 2016, p. 139); como terceiro ponto conceitual, a episteme "não se refere aos conhecimentos nem ao 
ponto de vista de sua forma racional nem ao de sua objetividade, mas às suas condições de possiblidade" (CASTRO, 2016, p. 139).

Em geral, "pode-se pensar a descrição da episteme como um olhar horizontal entre os saberes" (2016, p. 139), ou seja "por episteme se entende, de fato, o conjunto das relações que podem unir, em uma época dada, as práticas discursivas que dão lugar a figuras epistemológicas, a ciências, eventualmente a sistemas formalizados" (CASTRO, 2016, p. 140). É por meio da episteme que se compreende tantos os dispositivos como as práticas que constituem o sujeito.

Articular o conceito de episteme com resistência é ponderar uma outra forma de hermenêutica do sujeito. Sabe-se que a luta presente da resistência elencam três dimensões, a saber: "1) contra as formas de dominação ética, social ou religiosa; 2) contra as formas de exploração que separam os indivíduos o que eles produzem; 3) contra as formas de sujeição que vinculam o sujeito consigo mesmo e, desse modo, asseguram sua sujeição aos outros" (CASTRO, p. 288). Em todos os casos a resistência está em categorias de tencionar as profundezas da "iceberg" que se impõe. Logo, em postura de diagnosticar a realidade, é necessário repensar o fenômeno educação sob o viés destas problematizações.

Assim, a subjetividade, em perspectiva de Foucault, é construída em relação, a partir do entrelaçamento entre sujeitos. A disciplina pode ser o dispositivo de humanização do sujeito, entretanto, esta mesma disciplina, que busca solapar a barbárie, pode ser responsável em criar mais um selvagem, entretanto, cativo aos sistemas dominadores. A educação, em termos kantianos, é elemento inerente ao sujeito, porém, a educação não pode seguir princípios maquiavélicos e pragmáticos, mas, em vez disso, uma postura transformadora.

\section{CONSIDERAÇões FINAIS}

Algumas considerações finais, a fim de equacionar alguns indícios dos três autores rubricados: Kant, Adorno e Foucault. Em primeiro lugar, o elemento constitutivo inerente ao fenômeno da educação não pode ser perdido de vista. Pensar a educação é pensar o sujeito em 
suas categorias ontológicas. A educação não pode ser visto como sedimentada a vida, como bem apontou os autores, só pela educação se que supera toda e qualquer barbárie, porém, é por meio desta mesma educação que há perpetuação de barbáries.

O segundo aspecto a ser destacado dessa equalização é que a perspectiva crítica sobre a forma como a educação tem sido conduzida na contemporaneidade. Os textos kantianos destacam como a educação, em terras brasileiras, está pelo menos 3 séculos atrasadas, isso porque se faz educação em um tempo sob as premissas do passado. O obsoletismo na abordagem educacional não é um acidente, mas um projeto bem sucedido e intencional que gerou o cenário vigente da contemporaneidade. Por isso, pensar educação relevante é postura crítica.

Desta forma, em terceiro lugar, educar é, por si só, ato político. Vale a distinção entre o que se compreende por partidarismo político e ação política. A educação quando se põe a serviço de um sistema ideológico político, assume o papel de uma instituição prescritiva que nada se responsabiliza pelo ato de educar. A educação é ação política pois é o fenômeno que, ao humanizar o sujeito, coloca o si-mesmo em relação com o Outro. Este convívio, complexo como típico de toda e qualquer relação humana, é resquício de uma postura política. Portanto, educar é postura contra a despolitização que é mecanismo de alienação e castração do sujeito.

Assim, em quarto lugar, pensar educação é lançar vistas sobre a epistemologia que tem sido criada e desenvolvida na contemporaneidade. A verdade está diretamente ligada ao que se entende por ciência, por isso, a educação, por mais que siga o rigor epistêmico, não pode se tornar refém desta epistemologia, considerando que a verdade é um constructo histórico condicionada aos eventos e intencionalidades de um momento histórico. Portanto, pensar a educação é, por um lado, produção epistêmica, e, por outro lado, ruptura epistemológica.

Por fim, a atitude de resistência que a educação pode despertar nos sujeitos revela o quanto os docentes estão comprometidos com a humanidade, pois seguir o viés crítico e reflexivo da educação é lançar os sujeitos no oceanos de incertezas, o qual, em um primeiro momento, pode soar como perigoso, todavia, é nesta crise que o sujeito descobre 
o que não deveria perder de vista: o si-mesmo. Educar é potencializar o espírito de transgressão e, ao mesmo tempo, de solidariedade.

\section{REFERÊNCIAS}

ADORNO, T. W. Educação e emancipação. Rio de Janeiro: Paz e Terra, 2014.

CASTRO, E. Vocabulário de Foucault: um percurso pelos temas, conceitos e autores. Belo Horizonte: Editora Autêntica, 2016.

, E. Introdução a Foucault. Belo Horizonte: Editora Autêntica, 2015.

M. A hermenêutica do sujeito. São Paulo: Martins Fontes, 2018.

M. A ordem do discurso: aula inaugural no College de France, pronunciada em 2 de dezembro de 1970. São Paulo: Loyola, 2001.

GALLO, S. Governamentalidade democrática e Ensino de Filosofia no Brasil Contemporâneo. In.: Cadernos de Pesquisa. Vol. 42 n. 145, jan./abr.: São Paulo: Fundação Carlos Chargas, 2012. Disponível em < http://www.scielo.br/scielo.php?script=sci_ arttext\&pid=S0100-15742012000100005\&lng=pt\&tlng=pt $>$, acesso em Dezembro 2018.

GUTTING, G (Org.). Foucault. São Paulo: Editora Ideias Letras, 2016.

JOSGRILBERG, R., "Da formação de mundos à imaginação educadora", em Notandum, ano XV, n.30, setembro-dezembro de 2012.

KANT, I. Sobre a Pedagogia. São Paulo: Editora Unimep, 1996.

NIETZSCHE, F. Escritos sobre educação. São Paulo: Edições Loyola, 2003.

VEIGA-NETO, A. J. Foucault \& Educação. São Paulo: Editora Autêntica, 2007.

Revista Páginas de Filosofia, v. 8, n. 1-2, p. 69-77, jan/dez. 2019 